\title{
A meta-analysis of determinants of RFID adoption around the world
}

Organization, technology, and public policy

Sabinne Lee and Kwangho Jung

Graduate School of Public Administration, Seoul National University, Seoul, South Korea
Determinants of RFID adoption

Received 19 July 2016 Revised 1 October 2016 Accepted 6 October 2016

\begin{abstract}
Purpose - This paper aims to explore various factors associated with radio frequency identification (RFID) adoption with quantitative meta-analysis. More specifically, this paper attempts to measure key variables of RFID adoption derived from Rogers' innovation theory and further examines how state intervention influences the process of RFID adoption. First, this paper compares, relying on a meta-analysis, various mean effect sizes among technological, organizational and environmental factors (i.e. government-driven policies) that Rogers suggested in his innovation model.

Design/methodology/approach - In mean effect size analysis, this paper finds that the technological factor is the most powerful factor that affects the RFID adoption. The technological factor is statistically significant across all regions, including North America, Europe and Asia. The organizational factor is significant only in developing countries like Southeast Asian countries and East Asian countries. Environmental factors like government intervention for facilitating RFID adoption are strong enough only in Southeast Asia and Europe.

Findings - This paper finds that government's supportive policy is more effective in Europe but not in America, while external pressure is still more effective in Southeast Asia. These results implicate that developmentalism or government-driven policy can be effective not only in developing countries but also in the case of developed countries. In addition, this paper conducts a seemingly unrelated regression (SUR) analysis based on Fisher's standardized score.

Originality/value - In SUR analysis, this paper finds that the correlations between RFID adoption intention and three innovation factors vary across industrial areas. More specifically, the manufacturing area shows negative moderating effect on all three equations where correlations between Rogers' innovation factors and RFID adoption intention are meta-dependent variables. Also, RFID adoption is accelerated when the size of the firm is large or the location of the firm is in Southeast Asia. This result implicates that the aspect of technology adoption can be changed by region and type of industry.
\end{abstract}

Keywords RFID technology, Meta-analysis, Rogers' innovation model, Fisher's $Z$ score

Paper type Research paper

(C) Sabinne Lee and Kwangho Jung. Published in the Asia Pacific Journal of Innovation and Entrepreneurship. This article is published under the Creative Commons Attribution (CC BY 4.0) licence. Anyone may reproduce, distribute, translate and create derivative works of this article (for both commercial and non-commercial purposes), subject to full attribution to the original publication and authors. The full terms of this licence may be seen at: http:// creativecommons.org/licences/by/4.0/legalcode

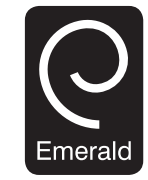

Asia Pacific Journal of Innovation and Entrepreneurship Vol. 10 No. 1,2016 pp. $67-90$ pp. 67-90
Emerald Group Publishing Limited
$2071-1395$ DOI 10.1108/APJE-12-2016-010 
APJIE

10,1

\section{Introduction}

Radio frequency identification (RFID) technology has a massive impact on citizens, organizations and society. The adoption of RFID technology has now become a global trend. The electromagnetic function of RFID tags and chips provides a basic building block for the Internet of Things. RFID technology integrates all machines, objects and virtual elements and makes them communicate with each other. RFID provides social innovation through thing-to-thing communications in various areas, including business-to-business. Thing-to-person communications include both business-to-consumer and governmentto-citizen. However, only a few research studies provide a comprehensive review of what factors are involved in the diffusion of RFID technology around the world. A systematic meta-analysis of the adoption of RFID can provide valuable insights to understand why organizations adopt new technology and what adoption routines and processes are. Many micro motives and macro trends in the diffusion of RFID around the world vary from organizations, institutions, cultures and other contextual factors. Based on a meta-analysis approach, we categorize various factors associated with the adoption of RFID in terms of organization barriers, technological benefits and government-driven policies.

We explore, relying on quantitative meta-analysis, what factors determine the adoption of RFID technology. More specifically, we conduct two kinds of quantitative meta-analysis in this study. First, we conduct quantitative meta-analysis that deals especially with RFID adoption. Jung and Lee (2015) provided a systematic literature review with a traditional way of reviewing published papers, focusing on public policy areas associated with RFID technology. However, unlike previous literature review papers, in this study, we try to adopt the meta-analysis technique to scrutinize the RFID adoption process in a more specific and quantitative way. As Gosall and Gosall (2012) defined, meta-analysis is "a quantitative evaluation of systematic literature review". Specifically, based on digital databases such as Google Scholar, Science Direct, Web of Science and ProQuest Central, we try to explore various determinants of RFID technology through quantitative meta-analysis to standardize and aggregate various types of statistical measurements (e.g. correlation coefficients, $F$-values, $t$-values and odd-ratios) from previous quantitative studies. We collect various types of statistical values derived from collected studies and convert them to Fisher's $Z$ score and standardized correlation score under three dimensions, including organizational factors, technological factors and environmental factors. We also implement a seemingly unrelated regression (SUR) model because three dependent variables in this meta-analysis are usually correlated to each other. In SUR analysis, we use these three dimensions as meta-dependent variables and explore how these meta-dependent variables vary depending on geographical regions, industry sectors, size of company and publication year.

Second, the scope of meta-analysis in this study is around the world. Most of the studies that deal with adoption determinants of innovative technology usually focused on a very restricted region and company, so it is very hard to aggregate the total effect size. However, we know the adoption of innovative technology like RFID technology is a global trend. After Wal-Mart adopted and commercialized its implementation in 2005, not only developed countries such as the USA but also developing countries like the Republic of Korea and Taiwan are trying to adopt a new method of management aggressively. We attempt to aggregate all the empirical results and analyze them across various countries. In addition, we test how the impacts of government-driven policies 
vary from developing to developed countries, including North America, Europe, East Asia and Southeast Asia.

To draw out necessity of this study, we want to stress on the strengths that quantitative meta-analysis has. The reason why we choose quantitative meta-analysis among various quantitative analysis techniques comes from the inherent strength of quantitative meta-analysis. As Meyer and Sullivan (2004) pointed out, usually it is hard to estimate total amount of effect size of independent variables because each study has different characteristics and backgrounds. So, it is necessary to aggregate all the empirical results and analyze them with a broader point of view. We can draw aggregated total amount of effect of adoption determinants of innovation diffusion factors when using quantitative meta-analysis. Also, when utilizing the quantitative meta-analysis method in the empirical study, we can figure out not only aggregate effects and calculate total effect size but also subdivide the effects by various standards. In this study, we deduct mean effect size by region and by three innovation diffusion factors.

This paper proceeds as follows. First, we review what factors are associated with adoption of new technology in terms of Rogers' innovation model. Second, we introduce how to standardize different types of statistical values to show the degree of relationship between adoption of RFID and independent variables such as organizational factors, technological factors and government-driven policies. All different types of statistical values are converted to Fisher's $Z$ score and finally reconverted to correlation. Third, we show how to collect previous literature based on a digital database for a meta-analysis and analytical framework with definitions of dependent and independent variables. Finally, we provide empirical analyses and possible interpretations of our empirical results.

\section{Literature review}

According to Marques et al. (2015), innovation is the transformation of knowledge of any kind into new products or services. Rogers' (1983) innovation diffusion theory would be the most famous and powerful model that can explain the determinants of innovation diffusion. Since Rogers published Diffusion of Innovations in 1983, many scholars began to study innovation diffusion (Bradford and Florin, 2003). Based on Rogers' original theory, scholars like Bradford and Florin (2003), O'Leary (2000), Davenport (1998) and Wen et al. (2009) set three factors as main factors that determine innovation technology adoption. Those factors are organizational characteristics factor, technological characteristics factor and environmental characteristics factor. In this section, we try to examine how Rogers and his colleagues define each factor based on the original theory.

\subsection{Organizational factor}

Scholars like Patterson et al. (2003) concentrate on the size of the firm. According to them, considering the size of the firm would be very important when it comes to technology adoption because usually big-sized firms keep the extra capacity to discover new technology and generate the economy of scale (Wen et al., 2009). Also, according to Grover and Goslar (1993), generally big-sized companies have more strong will to adopt brand-new technology because of their financial resources.Iacovou et al. (1995) argue that organizational readiness includes financial readiness and technological readiness. 

technology more easily. As Lai et al. (2014) point out from their study about RFID adoption in a Taiwanese hospital, adoption of brand-new technology can be interrupted if there are not enough financial resources. Positive correlation between financial readiness and technology adoption has been proved in many empirical research works, such as Krasnova et al. (2008). Technological readiness, like previous IT experience (Lai et al., 2014) and technological know-how (Fazel et al., 2011), is also an important factor that can affect the decision of technology adoption. According to Schmitt and Michahelles (2009), firms with fluent IT experience or know-how possess better ability to evaluate and manage innovative technology.

\subsection{Technological factor}

Technological factor comprises three different components: appropriateness, usefulness and benefit. According to Schmitt and Michahelles (2009), appropriateness and compatibility of technology is an important factor in determining technology adoption. To adopt technology successfully, a brand-new technology should be accommodated to current systems flexibly (Janz et al., 2005). Perceived benefit is also a very effective factor. When people perceive the benefit of technology, the speed of adoption becomes faster (Rogers, 1983). Scholars like Lee and Shim (2007) stress on the importance of perceived benefit because it is the most critical factor in RFID adoption from their perspective. Perceived usefulness is a little bit similar to perceived benefit in some ways, but what perceived usefulness would like to stress is somewhat different from perceived benefit. According to Zailani et al. (2015), perceived usefulness represents an individual's perceptions about technology that innovative methods will increase performance and efficiency. Some scholars like Wu and Wang (2005) and Yen et al. (2010) evaluate perceived usefulness as a more important factor than convenience because increased usefulness can even change the tendency of job performance and productivity in the end (Zailani et al., 2015).

\subsection{Environmental factor}

External pressure or competition from the outside market is set as an environmental factor according to Rogers (1983) and Bradford and Florin (2003). As Poston and Grabski (2001) pointed out, when one company adopted and started brand-new technology, other competitors started to feel impatient because they were anxious about the potential benefit that the first mover of technology might have and dispossess from them. The effect of external pressure has also been proved empirically by many previous studies. Scholars like Fitzek (2003), Jones et al. (2005) and Brown and Russell (2007) have figured out the power of competitive pressure in supply chains.

\subsection{State intervention}

Although Rogers (1983) did not include government's support in his innovation diffusion model, we do insert the variable about government's supportive policy that encourages firms to adopt brand-new technology. Technological determinism includes the belief that technology will change the whole society. Contrary to this scientism, defenders of social constructionism support the view that social factors decide the exact shape of a technology. But especially in developing countries like Asian countries, the government has the ability to mobilize social resources to drive their country more effectively and efficiently (Johnson, 1987). Also, technological change and globalization 
are not only a challenge for industrialized countries but also an opportunity (Lalkaka, 2009). Marques et al. (2015) pointed out that in the age of knowledge economy, successful economic development is intimately linked to a country's capacity from this sense. Therefore, sometimes, innovation technologies are adopted with the strong support of the government. In those cases, usually the power of the government is much bigger than the market power, so the market players play a very limited role in adopting brand-new innovation technology. We are trying to test the effect of government policy, especially in developing countries like Southeast Asia and East Asia at this point.

\section{Methodology and data}

\subsection{Quantitative meta-analysis}

A common quantitative meta-analysis is composed of three stages. As Wang and Bushman (1999) noted, the quantitative meta-analysis is a statistical research method that combines results of empirical studies by using the statistical methodology. To conduct our quantitative meta-analysis, we collect statistical values such as correlation coefficients and $t$-value from each published paper and code these values into the datasheet first. In this study, we collect four sorts of statistical values: $t$-value, $F$-value, odds ratio and correlation coefficient $(r)$, but other statistical values indicating the degree of correlation between independent variables and dependent variables are relevant enough to be used as raw data in meta-analysis. As one can see from Table I, if statistical values collected from original study are other than $r$ (in this study, $t$-value, $F$-value and odds-ratio), we convert those values to $r$ (correlation) first to draw Fisher's $Z$ score to compare statistical values with a different scale.

In the second stage, we convert collected statistical values to Fisher's $Z$ score for standardization because it is not possible to compare each literature's empirical results without standardization. In addition, the Fisher's $Z$ score has an advantage against Pearson's $r$ score. According to Jin (2015), the variance of effect size using Pearson's $r$ has skewed distribution. The left side of Figure 1 shows sample distribution of Pearson's $r$. As

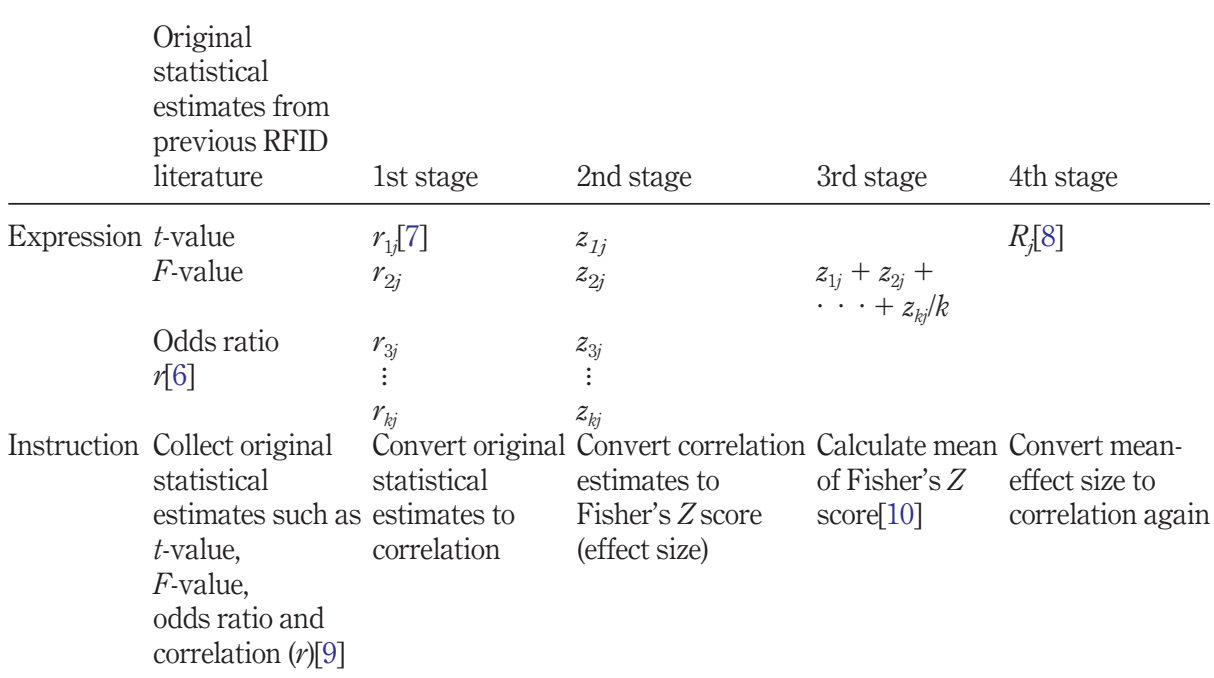

Original

estimates from

previous RFID

$r_{2 j}$

$z_{2 j}$

$z_{1 j}+z_{2 j}+$

Odds ratio

[6]

statistical

Convert original

estimates such as estimates to

$t$-value,

of Fisher's Z

effect size to
Determinants of RFID adoption 
APJIE

10,1

Figure 1.

Sample distributions of effect size using Pearson's $r$ and Fisher's $Z$ one can see from Figure 1, the variance of effect size becomes smaller as Pearson's $r$ is closer to 1[1]. Unlike this, when we standardize Pearson's $r$ using Fisher's $Z$, sample distribution can have a normal distribution[2] regardless of the size of Pearson's $r$ [3]. As we mentioned above, to make Fisher's $Z$ score, we have to convert statistical values we have kept from various empirical studies to $r$ (correlation), followed by applying Fisher's equation. If you convert all the statistical values to $r$, you can draw Fisher's $Z$ score using those correlations. Usually we call this Fisher's $Z$ score as "effect size". In the third stage, after all the statistical values we want to use for quantitative meta-analysis are standardized, we can calculate average effect size using standardized Fisher's $Z$ score. Finally, after calculating mean effect size, researchers can convert it to correlation values using Fisher's equation[4]. Through this calculation process, we obtain the size of aggregated effect size in a more simple and familiar way. If converted correlation is bigger than 0.4, we suppose the correlation between the independent and dependent variable is strong enough. Further, we can run multiple regression analysis using standardized Fisher's $Z$ score to study the moderating effect of characteristics of paper, such as publication year[5].

\subsection{Data collection}

Figure 2 shows the sequential flowchart we used for this study. Figure 2 illustrates six survey stages to collect previous literature on the adoption of RFID technology. First of all, we search previously published literatures about RFID adoption from various types of e-database. Most of the literature comes from Google Scholar (78 per cent) and the rest is from Science Direct, Web of Science and ProQuest Central. At the first stage, we collect 445 studies. And then at the second stage, we screen each paper by screening title and abstract. Studies that deal only with technological issues are excluded $(n=128)$. At the third stage, another 157 qualitative papers are excluded, because we use only papers with quantitative results with statistical values to standardize them to compare mean effect size. For this reason, studies that choose empirical research as methodology can only be utilized as a data resource. At the fourth stage, we exclude papers with irrelevant methodology like analytic hierarchy process or papers whose survey responders come from general consumers of RFID. We use only papers with survey respondents working in an industry sector such as IT, retail and manufacturing because we want to look at how practitioners from the industrial field respond to the diffusion of RFID technology. The total number of excluded papers is 85 in the fourth stage. In all, 75 research papers are left at the fifth stage and we start to code the data at this point. But among the 75
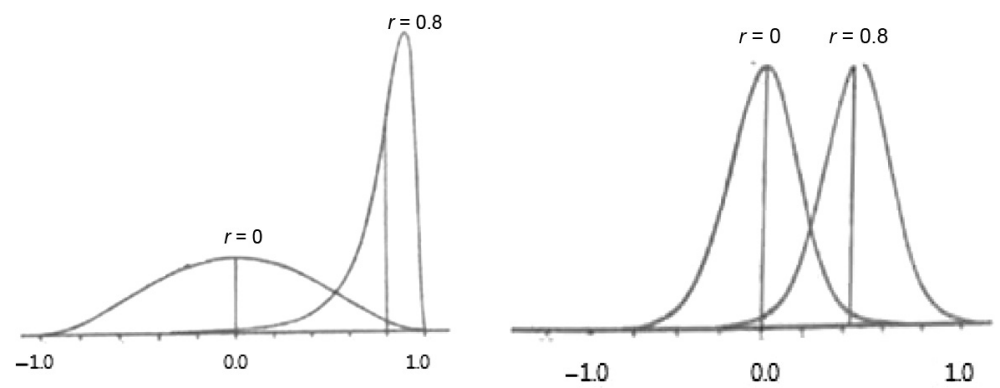

Source: Jin (2015) 


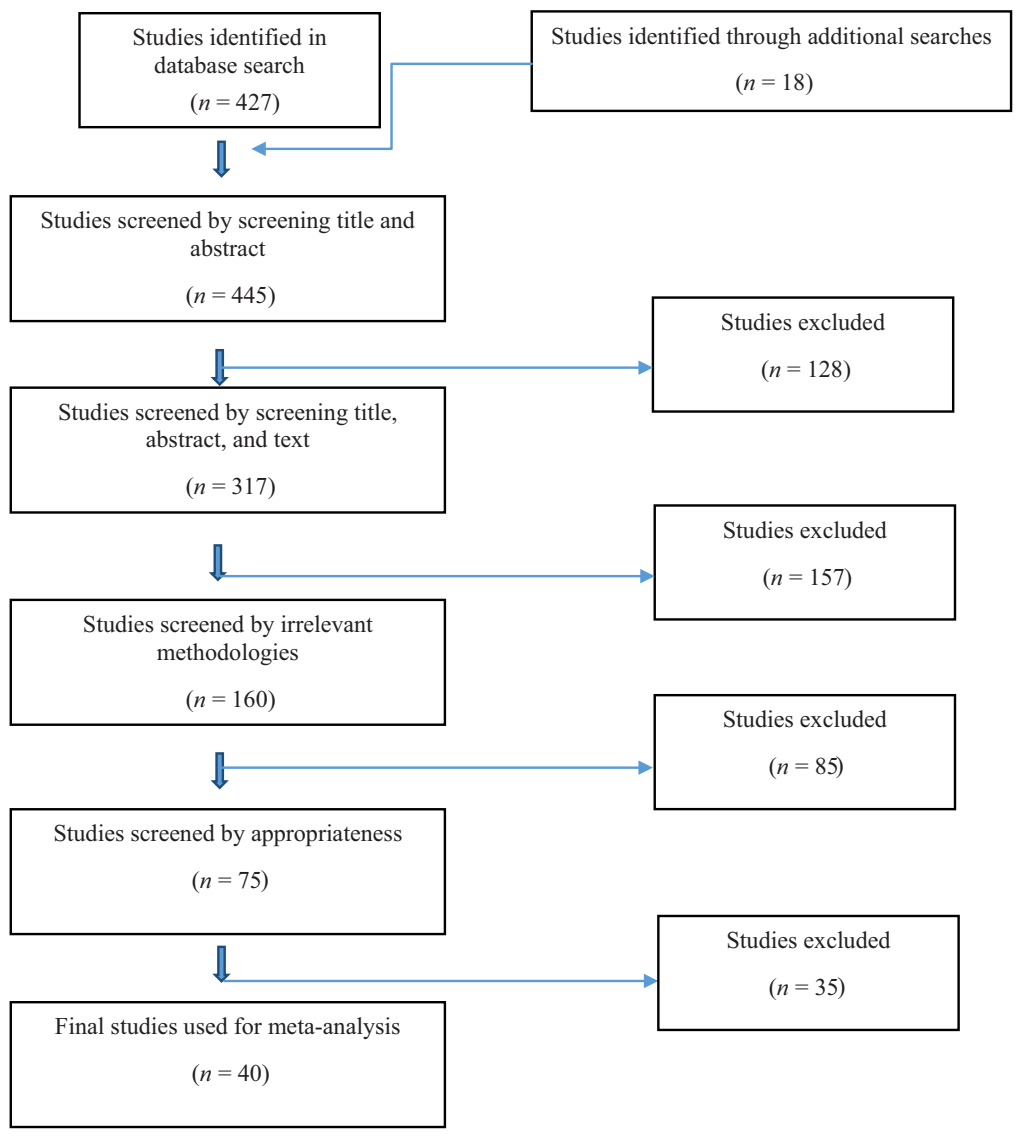

\section{Determinants of RFID adoption}

studies, there are ones that lack statistical values we need. In this case, we e-mailed each study's corresponding author to ask for data information. We include studies with corresponding author's reply to our data set, but if there is no sign of reply, we exclude them $(n=35)$. Finally, we obtain 40 empirical studies for our quantitative meta-analysis. The list of the literature we have collected for our quantitative meta-analysis study is attached in Appendix 2.

\subsection{Measurements}

We present the list of variables in our quantitative meta-analysis and explanation about their measurement in Table II. First, our meta-dependent variables in the quantitative meta-analysis represent the relationships between the dependent variable (i.e. willingness to adopt RFID) and independent variables such as organizational, technological and environmental factors provided by original studies. The scale of the relationship is measured by statistical values such as $t$-values, $F$-values and correlation coefficients $(r)$. We finally convert these values to Fisher's $Z$ scores to standardize the degree of the relationships derived from different types of statistics. Second, the 


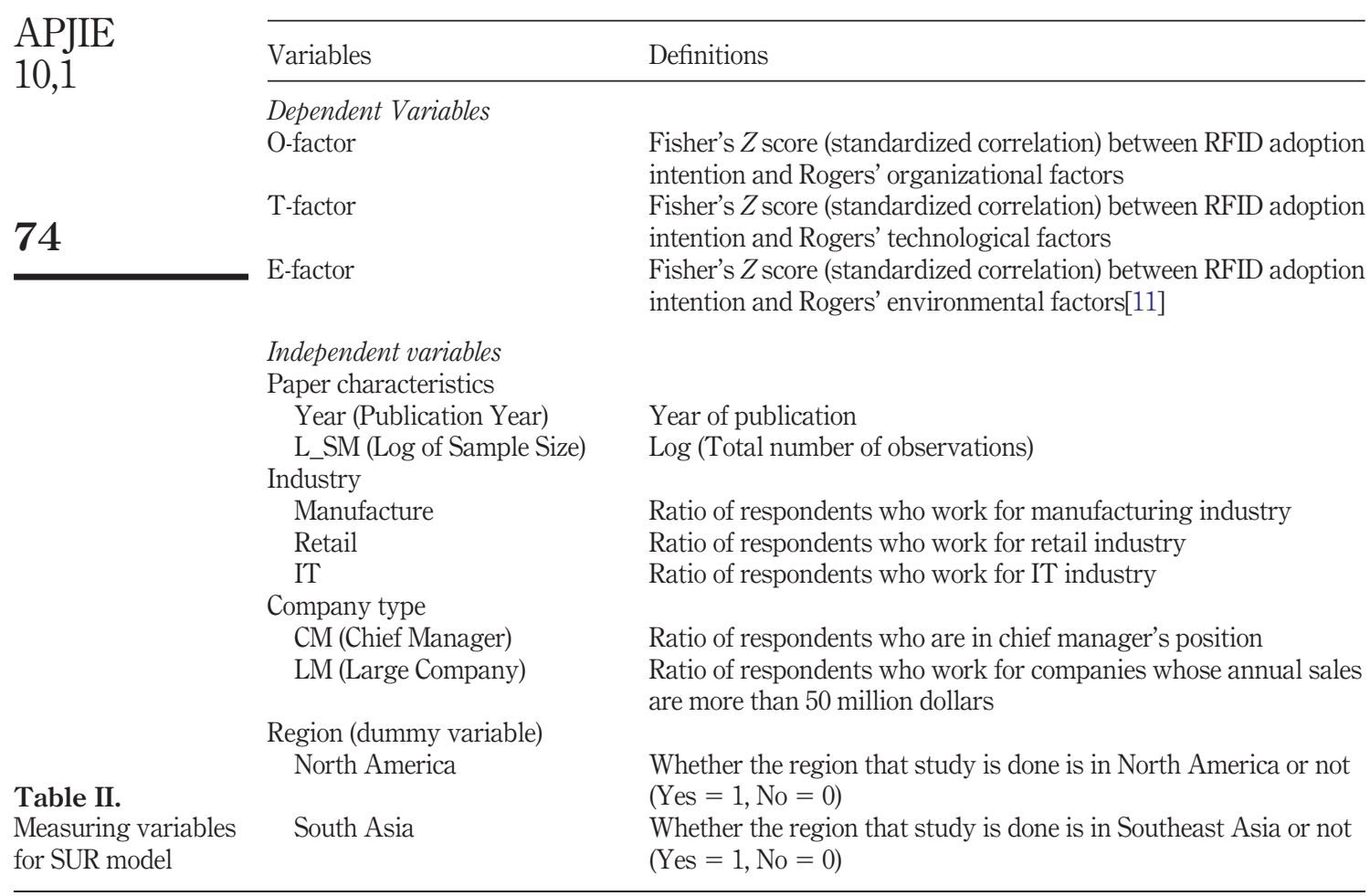

dependent variables to represent the intention to adopt RFID technology are measured by three different perspectives suggested by Rogers' (1983). The organizational factor is composed of firm size, financial readiness and technological readiness. Technological factors consist of appropriateness, perceived benefit, convenience and usefulness of RFID technology. Environmental factors contain external pressure from the outside market and competitors suggested by Roger's innovation model and state-driven policies for RFID adoption. We add the role of government that encourages the adoption of new technology as an environmental factor. It allows us to test whether the government can play a significant role in adopting new technology or not both in developed and developing countries. Third, we use four types of meta-independent variables. They include industry sector of survey respondents, company characteristics, region and year of publication and sample size (Figure 2).

\subsection{Analytical frame}

In this study, we adopt two different sorts of empirical strategies to figure out the determinants of RFID adoption. First of all, as we mentioned before, we calculate mean effect size using Fisher's standardized $Z$ score. After finishing mean effect size analysis, we conduct meta-SUR analysis using standardized score. Figure 3 shows analytical framework we use for meta-SUR analysis. As we mentioned above in the methodology part, in meta-regression analysis, the meta-dependent variable indicates the correlation between the independent variable and dependent variable from original studies. Also in 
meta-regression analysis, researchers set meta-independent variables as specific characteristics that each study has. For example, year of publication, region or country in which studies were done and characteristics of samples are usually used as meta-independent variables. As a meta-dependent variable is about correlation of original independent and dependent variables, meta-independent variable of meta-regression analysis can be understood as a moderating variable that moderates the relationship between the original independent and dependent variable.

In our meta-SUR analysis, the relationships between RFID adoption intention and three innovation diffusion factors that Rogers suggested are set as three meta-dependent variables. Meta-independent variables can be categorized in four categories: characteristics of paper, characteristics of industry, characteristics of company and characteristics of region.

\section{Empirical analysis}

\subsection{Mean effect size analysis}

In this section, we will suggest our empirical research results that draw from mean effect size analysis and meta-SUR analysis. Table III shows results from mean effect size analysis calculated under innovation diffusion factors. Based on Rogers' study in 1983, we have set organizational factor, technological factor and environmental factor as three main factors that can determine the adoption of innovative brand-new technology. As one can see from Table III, among organizational factors, technological readiness (0.429) of each organization turned out to be the most powerful factor. The average standardized Fisher's $Z$ score of organizational factors is 0.353 , and it can be converted to a correlation score, which is 0.339 . Among the technological factors, the perceived usefulness of RFID technology scored the highest Fisher's $Z$ score (0.544). Although perceived benefit won the second place, it also showed very strong correlation between RFID adoption intention and itself (0.479). The average Fisher's $Z$ score of technological factors is 0.481 . When we convert this mean effect size to correlation, followed by using Fisher's equation, the standardized correlation score is 0.447 . Finally, we perform mean effect size analysis using factors about environments that companies who have intention to adopt RFID have to face. Environmental factor is composed of two detailed

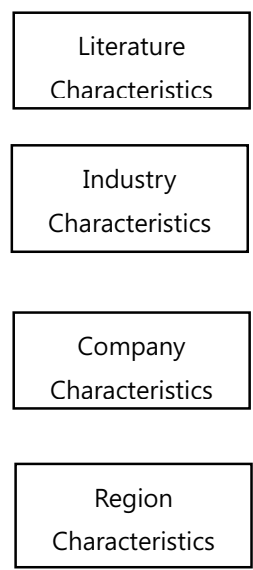

Determinants of RFID adoption

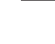




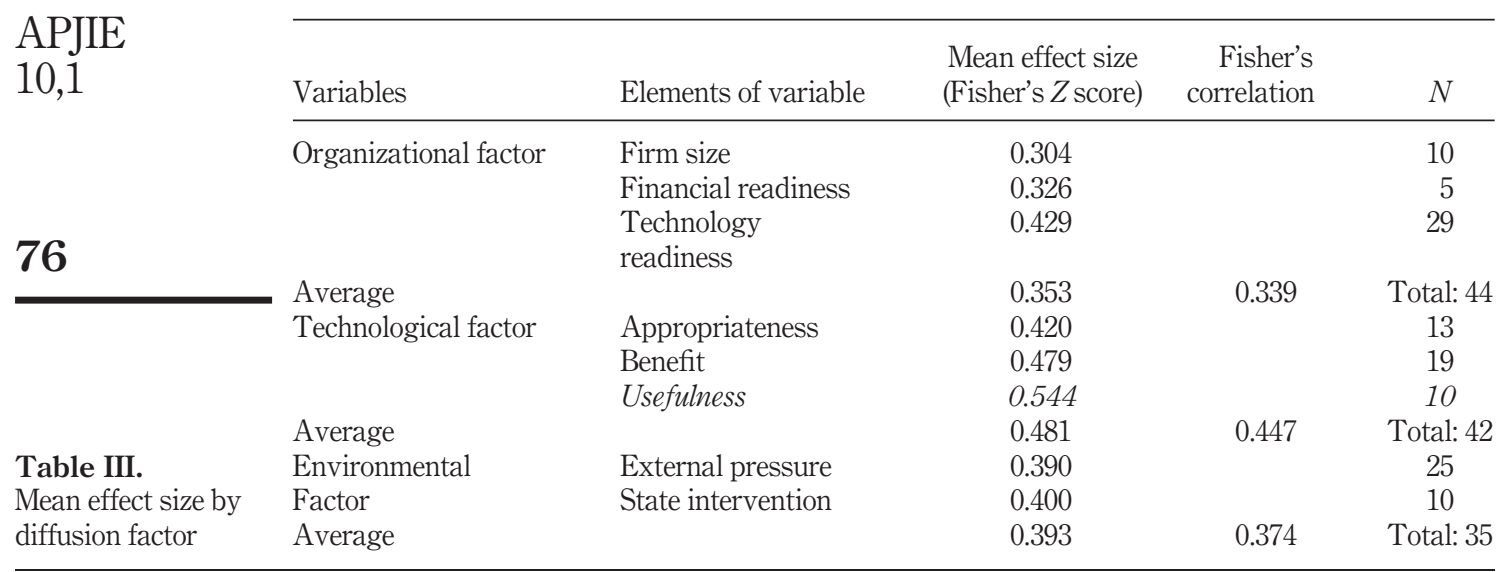

\begin{tabular}{|c|c|c|c|c|c|}
\hline Region & Innovation factor & $\begin{array}{l}\text { Mean effect } \\
\text { size(Fisher's } Z \\
\text { score) }\end{array}$ & $\begin{array}{r}\text { Fisher's } \\
\text { correlation }\end{array}$ & $N$ & Country \\
\hline \multirow[t]{3}{*}{ North America } & Technological & 0.518 & 0.476 & 3 & \multirow[t]{3}{*}{ USA } \\
\hline & Organizational & 0.278 & 0.271 & 5 & \\
\hline & Environmental & 0.313 & 0.303 & 3 & \\
\hline \multirow[t]{3}{*}{ East Asia } & Technological & 0.438 & 0.412 & 24 & \multirow{3}{*}{$\begin{array}{l}\text { South Korea, } \\
\text { China }\end{array}$} \\
\hline & Organizational & 0.445 & 0.418 & 24 & \\
\hline & Environmental & 0.343 & 0.330 & 17 & \\
\hline \multirow[t]{3}{*}{ Southeast Asia } & Technological & 0.529 & 0.485 & 8 & \multirow{3}{*}{$\begin{array}{l}\text { Taiwan, Malaysia, } \\
\text { Singapore }\end{array}$} \\
\hline & Organizational & 0.489 & 0.453 & 9 & \\
\hline & Environmental & 0.441 & 0.414 & 11 & \\
\hline \multirow[t]{3}{*}{ Europe } & Technological & 0.529 & 0.485 & 3 & \multirow{3}{*}{$\begin{array}{l}\text { UK, Germany, } \\
\text { Austria }\end{array}$} \\
\hline & Organizational & 0.032 & 0.032 & 3 & \\
\hline & Environmental & 0.524 & 0.481 & 2 & \\
\hline \multirow[t]{3}{*}{ The other } & Technological & 2.112 & 0.971 & 4 & \multirow[t]{3}{*}{ Brazil, Mixed } \\
\hline & Organizational & 0.553 & 0.503 & 3 & \\
\hline & Environmental & 1.069 & 0.789 & 2 & \\
\hline
\end{tabular}

factors: external pressure from the outside market and competitors and government's supportive policy. External pressure from the outside market has about 0.01 lower score point $(0.390)$ than government's policy factor $(0.400)$. The average effect size of external pressure factor and government policy factor is 0.393 , and it can be converted to Fisher's correlation score, which is 0.374 . In conclusion, among the three diffusion factors, technological factor is the most important and powerful factor.

We conduct mean effect size analysis again by adding region standard. We categorized regions in which published studies were done into four categories: North America (the USA), East Asia (ROK, China), Southeast Asia (Taiwan, Singapore, Malaysia) and Europe (Germany, the UK). In North America, the technological factor (0.476) turned out to be the most powerful factor, followed by environmental factor (0.303) and organizational factor (0.271). In East Asia, the organizational factor scores 
the highest Fisher's correlation, which is 0.418 , and it is 0.006 point higher than the technological factor (0.412). Fisher's correlation score of the environmental factor is not higher than 0.4 in East Asia. In Southeast Asia, all three factors turned out to have higher mean effect size than 0.4. Although all three factors are strong, but technological factor is the highest. Specifically, technological factor is the most influential factor in this mean effect size analysis (0.485). The next largest Fisher's correlation is organizational factor (0.453). Environmental factor is the last (0.414) but still larger than North America's and East Asia's. Fisher's correlation of technological factor is still

Determinants of RFID adoption strong enough (0.485) in Europe like other regions. Also, similar to what is shown in Southeast Asia, environmental factor is higher than 0.4 (0.481).

In sum, technological factor turned out to be the powerful factor in RFID adoption in North America, East Asia, Southeast Asia and Europe. However, significantly important innovation factors appear to be different depending on regions. Organizational factor consisting of technological readiness, financial readiness and firm size is significantly strong enough especially in developing countries like East Asian countries and Southeast Asian countries. As Becker (2004) pointed out, RFID tag is much more expensive than barcode, a traditional way of identification. Therefore, to adopt RFID technology and apply it relevantly, firms should have enough organizational resources first that most of the firms in developing countries lack. Our empirical result is similar to previous research studies in this sense. Also, unlike general myths, government's support is important in the European continent. When we split environmental factor into two parts and then perform mean effect size analysis for each, Fisher's correlation score of external pressure (0.446) is little bit stronger than government's supportive policy (0.401). Contrary to this result, in Europe, government's policy (0.717) is more important than external market pressure (0.146). Of course, as the number of observations in Europe is small to generalize this result, this result implies that in countries like the UK, where government-driven policy prevailed compared with any other European country, the government might strongly push firms into adopting new technology like RFID.

\subsection{SUR analysis}

We carry out an exploratory meta-SUR analysis to figure out what kinds of characteristics of each literature affect the relationship between RFID adoption and three innovation diffusion factors using standardized Fisher's $Z$ score. Table $V$ shows the results of meta-SUR analysis[12]. The first column of each model represents the equation where correlation between RFID adoption intention and organizational factor is a meta-dependent variable. The second and third columns use the relationship between RFID adoption and technological factors and the relationship between RFID adoption and environmental factors as their meta-dependent variables. We use nine independent variables across four categories including paper publication, survey respondents, company characteristics and region derived from published papers. Paper characteristics are about publication year and log of number of observations. Industry characteristics include the ratio of responders from a specific sector (manufacture, retail, IT). "Chief manager" variable in the company category is about the ratio of responders in the chief manager position, and "Largecom" variable represents the ratio of responders from a large-sized company. If the total sales of the company that the 


\begin{tabular}{|c|c|c|c|c|c|}
\hline \multirow[t]{2}{*}{$\begin{array}{l}\text { APJIE } \\
10,1\end{array}$} & \multicolumn{2}{|c|}{ Independent variables } & $\begin{array}{l}\text { Model } 1 \\
\text { (O-factor) }\end{array}$ & $\begin{array}{c}\text { Dependent variable } \\
\text { Model } 2 \\
\text { (T-factor) }\end{array}$ & $\begin{array}{l}\text { Model } 3 \\
\text { (E-factor) }\end{array}$ \\
\hline & Publication paper & $\begin{array}{l}\text { Publication-year } \\
\text { L_SN (Log of } \\
\text { sample size) }\end{array}$ & $0.106(0.094)$ & $0.000(0.013)$ & $\begin{array}{l}0.000(0.009) \\
0.037(0.047)\end{array}$ \\
\hline & Industry & Manufacture & $-0.010 *(0.004)$ & $-0.009 * * *(0.003)$ & $-0.008 * * *(0.003)$ \\
\hline \multirow{10}{*}{$\begin{array}{l}\text { Table } \mathbf{V} \text {. } \\
\text { Meta-SUR analysis } \\
\text { result }\end{array}$} & & $\begin{array}{l}\text { Retail } \\
\text { IT }\end{array}$ & $\begin{array}{l}0.007(0.006) \\
0.001(0.002)\end{array}$ & $\begin{array}{l}0.005(0.003) \\
0.001(0.002)\end{array}$ & $\begin{array}{l}0.005(0.003) \\
0.001(0.002)\end{array}$ \\
\hline & Company & Chief Manager & $-0.006(0.009)$ & & \\
\hline & & $\begin{array}{l}\text { LC } \\
\text { (large company) }\end{array}$ & $\begin{array}{l}0.004^{*} \\
(0.002)\end{array}$ & $\begin{array}{l}0.003^{*} \\
(0.002)\end{array}$ & $\begin{array}{l}0.003^{*} \\
(0.002)\end{array}$ \\
\hline & Region & North America & $-0.024(0.247)$ & $-0.180(0.117)$ & $-0.172(0.106)$ \\
\hline & & Southeast Asia & $0.424(0.330)$ & $0.200 *(0.100)$ & $0.224 *(0.092)$ \\
\hline & Intercept & $-0.282(0.440)$ & $0.242(26.868)$ & $2.384(17.168)$ & \\
\hline & $R^{2}$ & & 0.5720 & 0.5450 & 0.5576 \\
\hline & $\chi^{2}$ & & 57.02 & 44.36 & 51.09 \\
\hline & Sample size & & 37 & 37 & 37 \\
\hline & \multicolumn{5}{|c|}{ Notes: $* p<0.1 ; * * p<0.01 ; * * * p<0.005$} \\
\hline
\end{tabular}

responder works for are over 50 million dollars, we perceived it as a large company. Regional variable has two detailed variables: North America and Southeast Asia.

As you can see from Table V, different results are found depending on the meta-dependent variable. In all three regression models, manufacture and Largecom variables turned out to be significant, but each variable shows a different sign. Manufacture variable has negative moderating effects on the meta-dependent variable contrary to Largecom in all three regression models. It implies that manufacturing firms are reluctant to adopt RFID technology even if organizational factors like financial readiness and technological readiness are prepared enough. This result is similar to what Bhattacharya et al. (2008) suggested[13]. In the case of the Largecom variable, it has positive moderating effects on the correlations between the organizational factor and RFID adoption in all three regression models. This result suggests that firms with both large amount of sales and sufficient financial/technical resources are more likely to adopt RFID technology than those without them[14]. In addition, Southeast Asia variable showed positive moderating effects in the second and third equations. This implies that firms in Southeast Asian countries are more likely to adopt RFID technology thanks to the technological factor and environmental factor.

\section{Conclusion and implications}

We review and analyze various empirical determinants of the adoption of RFID technology from 40 empirical studies published since 1983. More specifically, we conducted two different sorts of empirical meta-analyses. First, we calculated and compared various sizes of mean effect across four continental regions, i.e. North America, East Asia, Southeast Asia and Europe. We also compared three different sizes of mean effect among organizational, technological and environmental diffusion factors from Rogers' innovation theory. Second, we did meta-SUR analysis to identify what 
characteristics in the 40 RFID studies affect the degree of correlations (i.e. meta-dependent variables in the SUR model) between innovation factors from organizational, technological and environmental dimensions and RFID adoption intention. We also tested how government policy is related to the degree of correlation between Rogers' innovation factors and RFID adoption intention.

Our meta-analyses provide five key findings. First, technological factor is the most powerful factor in adopting RFID technology, followed by environmental factor and organizational factor, respectively. Second, technological usefulness scored the highest Fisher's $Z$ score among the three innovation factors, and its score appeared to be significant and important in all four regions, including North America, East Asia, Southeast Asia and Europe. This implies that firms have adopted RFID technology mostly based on its technological usefulness, appropriateness and convenience rather than environmental and organizational factors. Third, organizational factor is important especially in developing countries like East Asia and Southeast Asia. As innovative technologies like RFID need a relatively high level of financial readiness than traditional technology, firms in developing countries may make decisions based on the richness of their budget. Fourth, environmental factor is important in Southeast Asia and Europe. Government-driven policy variable is much more important in Europe than in Southeast Asia. On the other hand, the correlation score of external pressure from the outside market is higher in developing countries than in Europe. Fifth, our SUR analysis shows that manufacture variable has negative signs in all three equations. Large company and Southeast Asia variables have significantly positive effects on the correlation between organizational factor/technological factor/environmental factor and RFID adoption.

We can draw three implications from our quantitative meta-analysis. First, technological factor appeared to be the most powerful factor that can affect RFID adoption intention. When we calculate mean effect size of each factor by region (North America, East Asia, South Asia, Europe), technological factor won the first place in every region except East Asia. While organizational and institutional factors are important, technological usefulness and benefits are still the most important factors to attract new technology. Second, government-driven policies to encourage the adoption of RFID technology affect European countries the most. The size of the policy effect is much bigger in Europe than in developing countries like South Asian countries. This implies that public policy can play quite a critical role in even developed countries like the UK. As Chen (2014) described, national innovation is becoming a key issue related to national competitiveness not only to developing countries but also to G7 countries. Third, in meta-SUR analysis, we figure out that correlation between RFID adoption intention and three independent variables may vary from different industry sectors, implying industrial contexts can matter in introducing RFID technology.

This study has several limitations to explore the whole picture of what factors are associated with the adoption of RFID technology across various countries over time. First of all, we have rather small number of observations collected from 40 different studies. Generally, the size of observation of most of the quantitative meta-regression analyses is not quite large. According to Hunter and Schmidt (2004), "In meta regression, the sample size is often as small as 15, 20 and 30". However, our small number of data points cannot be enough for performing regression analysis in some ways. Second,
Determinants of RFID adoption 

published only when they make reviewers and publishers feel satisfied. For this reason, previously published papers collected to be used as data in quantitative meta-analysis have publication bias. Future meta-analysis should add future published papers into a data set and try to carry out more detailed analysis than ours. Also, further research is required to consider more various sources of published papers about RFID adoption to minimize publication bias. Finally, we need to consider historical and institutional contexts embedded in firms to introduce RFID technology (Jeon et al., 2015), depending on industry- and country-specific effects. In addition, we need to examine various hidden costs involved in the introduction of RFID technology (Barut et al., 2006). Further research is required to explore what kinds of hidden costs are associated with the adoption of RFID technology and their influence.

\section{Notes}

1. The equation for calculating the variance of effect size using Pearson's $r: V_{r}=(1-$ $\left.r^{2}\right) / n-1$.

2. The equation for calculating Fisher's $Z=0.5 \times \ln \left(1+r^{2} / 1-r\right)$.

3. The variance of Fisher's $Z$ can be calculated through this equation: $V_{z}=1 / n-3$. As the variance of Fisher's $Z$ is not a function of Pearson's $r$, it can have normal distribution regardless of the size of Pearson's $r$.

4. When we convert Fisher's $Z$ score to correlation value, we use this equation: $r=e^{2 z}-$ $1 / e^{2 z}+1$.

5. There are three big differences between normal multiple regression and meta-regression analysis. First, the dependent variable used in meta-regression-analysis is standardized correlation between dependent and independent variables reported in original studies. Specifically, effect size or Fisher's $Z$ score, calculated in the second stage in Table I, is used as the meta-dependent variable. Therefore, meta-independent variables in fact are the moderating variables that affect the relationship between original independent and dependent variable. Second, in meta-regression-analysis, what independent variables stand for are the characteristics of literature, such as publication year, country, descriptive statistics of sample, etc. Third, in meta regression analysis, number of observations of variance is used as weight to revise potential biases.

6. There is no need to give any statistical conversion process in the second stage if statistical values collected in the first stage are in correlation $(r)$.

7. " $\mathrm{j}$ " represents groups or categories under which the researcher wants to calculate the mean effect size. For example, in this study, we calculated mean effect sizes by three diffusion factors (organizational, environmental, technological) and regions (North America, East Asia, Southeast Asia, Europe, etc.).

8. This is the mean effect size of group “ $\mathrm{j}$ ”.

9. The statistical values collected from original studies represent the degree of correlation between the original independent variable and dependent variable.

10. As we mentioned above, in meta-analysis, researchers usually convert correlation to Fisher's $Z$ score that can have normal distribution regardless of the sample size. 
11. Rogers' environmental innovation factors include external pressure. We also add an environmental variable of RFID adoption, which is a government-driven public policy to induce or facilitate RFID innovation.

12. There are several statistical criteria to use the SUR method, rather than the ordinary least squares method. As the $p$-value of the Breusch-Pagan test was very close to 0 , we can reject null hypothesis of the Breusch-Pagan test. This means that we should use the SUR model rather than multiple meta-regression. Also, as we have singular covariance matrix of errors,

Determinants of RFID adoption procedure for handling this singularity problem is to drop an arbitrary equation and then estimate the remaining equation". We used a different set of independent variables for each innovation factor, according to Takada et al. (1995).

13. In their study comparing RFID adoption in retail and manufacturing sectors, Bhattacharya et al. (2008) pointed out that it is widely believed that technology will bring the retail sector great amount of benefits, while the manufacturing sector has to bear high cost and little return. Also, in this study, most of the survey responders who work in the manufacturing industry are from developing countries like Southeast Asia. In the manufacturing industry in developing countries, delicate, high level of identifying technology is not needed because most of the manufacturing firms in developing countries perform simple, subcontracting manufacturing tasks with the investment from developed countries (Jun, 2008).

14. According to Lee et al. (2006), firms with large amount of sales are more likely to adopt brand-new technology because they have the ability to grasp technological potential such as appropriateness, usefulness and perceived benefit faster. Also, scholars like Pierce (2008) pointed out that big-sized firms are inevitably sensitive to external environment factors like market turbulence because the "ecosystem" can generate not only financial benefits but also losses.

\section{References}

Barut, M., Brown, R., Freund, N., May, J. and Reinhart, E. (2006), "RFID and corporate responsibility: hidden costs in RFID implementation”, Business and Society Review, Vol. 111 No. 3, pp. 287-303.

Becker, C. (2004), “A new game of leapfrog? RFID is rapidly changing the product-tracking process. Some say the technology-once costs drop-could displace bar-coding", Modern Healthcare, Vol. 34 No. 28, pp. 38-40.

Bhattacharya, M. (2015), "A conceptual framework of RFID adoption in retail using Rogers stage model”, Business Process Management Journal, Vol. 21 No. 3, pp. 517-540.

Bhattacharya, M., Chu, C.H. and Mullen, T. (2008), "A comparative analysis of RFID adoption in retail and manufacturing sectors", IEEE International Conference on RFID, Las Vegas, NV, IEEE, pp. 241-249.

Bradford, M. and Florin, J. (2003), "Examining the role of innovation diffusion factors on the implementation success of enterprise resource planning systems", International Journal of Accounting Information Systems, Vol. 4 No. 3, pp. 205-225.

Brown, I. and Russell, J. (2007), "Radio frequency identification technology: an exploratory study on adoption in the South African retail sector", International Journal of Information Management, Vol. 27 No. 4, pp. 250-265. 
APJIE 10,1

Caldeira Pedroso, M., Zwicker, R. and Alexandre de Souza, C. (2009), "RFID adoption: framework and survey in large Brazilian companies", Industrial Management \& Data Systems, Vol. 109 No. 7, pp. 877-897.

Chen, K.C. (2014), "Exploring the national innovation policy of G7 countries and global research innovation output", Asia Pacific Journal of Innovation and Entrepreneurship, Vol. 7 No. 2, pp. 9-40.

Davenport, T.H. (1998), "Putting the enterprise into the enterprise system", Harvard Business Review, Vol. 76 No. 4, pp. 121-131.

Fazel, A., Forouharfar, A. and Fazel, A. (2011), "Measuring readiness for RFID adoption: reflection from Iranian supply chain companies", African Journal of Business Management, Vol. 5 No. 10, pp. 3844-3857.

Fitzek, D. (2003), Application of RFID in the Grocery Supply Chain: Universal Solution for Logistics Problems in the CPG Industry or a Mere Hype, University of St. Gallen Press, St. Gallen.

Goebel, C., Tribowski, C. and Günther, O. (2009), "Adoption of cross-company RFID: an empirical analysis of perceived influence factors", ECIS2009 Proceedings, pp. 1867-1878.

Gosall, N.K. and Gosall, G.S. (2012), The Doctor'S Guide to Critical Appraisal, PasTest, Cheshire.

Goswami, S., Teo, H.H. and Chan, H.C. (2008), "Real options from RFID adoption: the role of institutions and managerial mindfulness", ICIS 2008 Proceedings, p. 128.

Grover, V. and Goslar, M.D. (1993), "The initiation, adoption, and implementation of telecommunications technologies in US organizations", Journal of Management Information Systems, Vol. 10 No. 2, pp. 141-163.

Ha, O.K., Ha, D.I., Park, D.J., Lee, K.G. and Choi, C.H. (2011), "Decision making model for the introduction of RFID by food and beverage industry using logit model", The Journal of the Korean Institute of Intelligent Transport Systems, Vol. 10 No. 1, pp. 91-100.

Hunter, J.E. and Schmidt, F.L. (2004), Methods of Meta-Analysis: Correcting Error and Bias in Research Synthesis, Sage Publications.

Iacovou, C.L., Benbasat, I. and Dexter, A.S. (1995), "Electronic data interchange and small organizations: adoption and impact of technology”, MIS Quarterly, pp. 465-485.

Janz, B.D., Pitts, M.G. and Otondo, R.F. (2005), "Information systems and health care-II: back to the future with RFID: lessons learned-some old, some new", Communications of the Association for Information Systems, Vol. 15 No. 1, p. 7.

Jeon, J.H., Kim, S.K. and Koh, J.H. (2015), "Historical review on the patterns of open innovation at the national level: the case of the roman period", Journal of Open Innovation: Technology, Market, and Complexity, Vol. 1 No. 1, p. 1.

Jeong, S.C., Yoon, E.J. and Lee, D.Y. (2011), “The effect of perceived risk for the RFID acceptance intention”, The E-Business Studies, Vol. 12 No. 2, pp. 411-429.

Jin, Y. (2015), Meta Analysis Using STATA, Korea University Press, Seoul.

Johnson, C. (1987), "Political institutions and economic performance: the government-business relationship in Japan, South Korea, and Taiwan”, The Political Economy of the New Asian Industrialism, Cornell University Press, New York, NY.

Jones, M.A., Wyld, D.C. and Totten, J.W. (2005), "The adoption of RFID technology in the retail supply chain”, The Coastal Business Journal, Vol. 4 No. 1, pp. 29-42.

Jun, S.H. (2008), "The determinants of FDI to developing countries: a panel data analysis, 2000-2009", Journal of International Trade and Industry Studies, Vol. 16 No. 4, pp. $63-87$. 
Jung, K. and Lee, S. (2015), “A systematic review of RFID applications and diffusion: key areas and public policy issues", Journal of Open Innovation: Technology, Market, and Complexity, Vol. 1 No. 1, p. 1.

Kim, K.H., Shin, S.J., Choi, S.Y., Yeo, J.H. and Kang, K.S. (2008), "A study on economical introduction of RFID system in the small and medium 3rd party logistics", Journal of Korea Safety Management and Science, Vol. 10 No. 3, pp. 117-126.

Kim., S. (2010), "Determinants impacting the adoption and implementation of RFID technology and the moderating effect of organizational readiness", The Journal of Information Systems, Vol. 19 No. 1, pp. 149-177.

Kim., S. H. (2008), "An empirical study of factors influencing organizational intention to use RFID technology and the moderating effect of presence of champions", Journal of Business Research, Vol. 23 No. 3, pp. 139-171.

Kim, S. and Garrison, G. (2010), “Understanding users' behaviors regarding supply chain technology: determinants impacting the adoption and implementation of RFID technology in South Korea”, International Journal of Information Management, Vol. 30 No. 5, pp. 388-398.

Kim, S.H. and Song, Y.M. (2011), "The effect of factors influencing RFID adoption and performance and the moderating effect of environment uncertainty within supply chain", Journal of the Korea Society Industrial Information System, Vol. 16 No. 3, pp. 101-119.

Krasnova, H., Weser, L. and Ivantysynova, L. (2008), “Drivers of RFID adoption in the automotive industry", AMCIS 2008 Proceedings, p. 287.

Lai, H.M., Lin, I.C. and Tseng, L.T. (2014), "High-level managers' considerations for RFID adoption in hospitals: an empirical study in Taiwan”, Journal of Medical Systems, Vol. 38 No. 2, pp. 1-17.

Lalkaka, R. (2009), "National innovation systems: the roles of academia, enterprises and state", Asia Pacific Journal of Innovation and Entrepreneurship, Vol. 3 No. 2, pp. 5-28.

Lee, C.P. and Shim, J.P. (2007), "Journal of Information: an exploratory study of radio frequency identification (RFID) adoption in the healthcare industry", European Journal of Information Systems, Vol. 16 No. 6, pp. 712-724.

Lee, J.B., Lee, S.C., Lee, H.S. and Lee, H.C. (2006), “An analysis of environmental factor and organization factors in RFID adoption: based on moderating effect of firms", The Journal of Information Systems, Vol. 15 No. 3, pp. 213-232.

Lee, J.B., Lee, H.S., Jang, Y.H. and Lee, S.C. (2006), “A research on the affecting factor for adopting RFID as a technology innovation", Journal of the Korean Operations Research and Management Science Society, Vol. 31 No. 2, pp. 41-55.

Lee, K.W. and Hong, S.J. (2011), "A study of effect of organizational culture on internet based technology adoption”, Korea Society of Management Information Systems.

Lee, M.S. (2007), "The effect of trust and perceived risk on the RFID”, Journal of Industrial Economics and Business, Vol. 20 No. 6, pp. 2509-2538.

Lee, M.S. (2008), "An empirical study on the effect of trust and RFID technology acceptance", Korean Journal of Business Administration, Vol. 16 No. 1, pp. 47-81.

Lee, M.S. and Moon, S.H. (2009), "The empirical study about factors on RFID acceptance: focus on the employees in enterprise or public institution", The Journal of Internet Electronic Commerce, Vol. 9 No. 1, pp. 281-305.

Lim, S.H. (2009), “An empirical study of RFID adoption: role of collaboration and technological fit”, Korea Logistics Review, Vol. 19 No. 1, pp. 97-127. 
APJIE

10,1

Lim., S.H. (2011), "Impact of managerial and technical IT capability in fits and intention to adopt RFID: a cross-national comparison study", Korea Logistics Review, Vol. 21 No. 2 , pp. 27-58.

Lim, S.H. and Chung, N.H. (2010), "The effect of firm's IT capability on RFID adoption success: the role of expected benefit, trust, and risk", Korean Journal of Business Administration, Vol. 23 No. 5, pp. 2543-2563.

Lin, C.Y. and Ho, Y.H. (2009), "RFID technology adoption and supply chain performance: an empirical study in China's logistics industry”, Supply Chain Management: An International Journal, Vol. 14 No. 5, pp. 369-378.

Madlberger, M. (2009), "A model of antecedents of RFID adoption intention in the supply chain", System Sciences, 2009.HICSS'09 42nd Hawaii International Conference, January, IEEE, pp. 1-10.

Marques, J.S., Yigitcanlar, T. and da Costa, E.M. (2015), "Australian innovation ecosystem: a critical review of the national innovation support mechanisms", Asia Pacific Journal of Innovation and Entrepreneurship, Vol. 9 No. 2, pp. 3-28.

Marques, J.S., Yigitcanlar, T. and Eduardo, M.D.C. (2015), "Incentivizing innovation: a review of the Brazilian federal innovation support programs", Asia Pacific Journal of Innovation and Entrepreneurship, Vol. 9 No. 1, pp. 31-56.

Meyer, B.D. and Sullivan, J.X. (2004), "The effects of welfare and tax reform: the material well-being of single mothers in the 1980s and 1990s", Journal of Public Economics, Vol. 88 No. 7, pp. 1387-1420.

O’Leary, D.E. (2000), Enterprise Resource Planning Systems: Systems, Life Cycle, Electronic Commerce, and Risk, Cambridge University Press, Cambridge.

Osyk, B.A., Vijayaraman, B.S., Srinivasan, M. and Dey, A. (2012), "RFID adoption and implementation in warehousing", Management Research Review, Vol. 35 No. 10, pp. 904-926.

Park, D.J., Ha, O., Lee, K., Kim, S. and Rho, J. (2010), “Analysis of effects of introducing RFID into ULS Pallet”, Seoul Studies, Vol. 11 No. 2, pp. 219-228.

Park, Y.J. and Rim, M.H. (2009), "An analysis on the factors affecting perception, adoption and implementation of RFID technology”, Korean Management Science Review, Vol. 26 No. 3, pp. 205-221.

Patterson, K.A., Grimm, C.M. and Corsi, T.M. (2003), “Adopting new technologies for supply chain management”, Transportation Research Part E: Logistics and Transportation Review, Vol. 39 No. 2, pp. 95-121.

Pierce, L. (2008), "Big losses in ecosystem niches: how core firm decisions drive complementary product shakeouts", Strategic Management Journal, Vol. 30 No. 3, pp. 323-347.

Poston, R. and Grabski, S. (2001), "Financial impacts of enterprise resource planning implementations", International Journal of Accounting Information Systems, Vol. 2 No. 4, pp. 271-294.

Ramanathan, R., Ramanathan, U. and Ko, L.W.L. (2014), “Adoption of RFID technologies in UK logistics: moderating roles of size, barcode experience and government support”, Expert Systems with Applications, Vol. 41 No. 1, pp. 230-236.

Rogers, E.M. (1983), Diffusion of Innovations, Free Press, New York, NY.

Schmitt, P. and Michahelles, F. (2009), "Status of RFID/EPC adoption”, Auto-ID Labs White Paper, March. 
Takada, H., Ullah, A. and Chen, Y.M. (1995), "Estimation of the seemingly unrelated regression model when the error covariance matrix is singular", Journal of Applied Statistics, Vol. 22 No. 4, pp. 517-530.

Thiesse, F., Staake, T., Schmitt, P. and Fleisch, E. (2011), "The rise of the "next-generation bar code': an international RFID adoption study”, Supply Chain Management: An International Journal, Vol. 16 No. 5, pp. 328-345.

Tsai, M.C., Lee, W. and Wu, H.C. (2010), "Determinants of RFID adoption intention: evidence from Taiwanese retail chains”, Information \& Management, Vol. 47 No. 5, pp. 255-261.

Tsai, W.C. and Tang, L.L. (2012), "A model of the adoption of radio frequency identification technology: the case of logistics service firms", Journal of Engineering and Technology Management, Vol. 29 No. 1, pp. 131-151.

Wang, M.C. and Bushman, B.J. (1999), Integrating Results Through Meta-Analytic Review Using SAS Software, SAS Institute, Cary, NC.

Wang, Y.B., Lin, K.Y., Chang, L. and Hung, J.C. (2011), “A diffusion of innovations approach to investigate the RFID adoption in Taiwan logistics industry", Journal of Computers, Vol. 6 No. 3, pp. 441-448.

Wen, L., Zailani, S. and Fernando, Y. (2009), "Determinants of RFID adoption in supply chain among manufacturing companies in China: a discriminant analysis", Journal of Technology Management \& Innovation, Vol. 4 No. 1, pp. 22-33.

Whitaker, J., Mithas, S. and Krishnan, M.S. (2007), "A field study of RFID deployment and return expectations", Production and Operations Management, Vol. 16 No. 5, pp. 599-612.

Wu, J.H. and Wang, S.C. (2005), "What drives mobile commerce? An empirical evaluation of the revised technology acceptance model", Information \& Management, Vol. 42 No. 5, pp. 719-729.

Wu, X. and Subramaniam, C. (2011), "Understanding and predicting radio frequency identification (RFID) adoption in supply chains", Journal of Organizational Computing and Electronic Commerce, Vol. 21 No. 4, pp. 348-368.

Yen, D.C., Wu, C.S., Cheng, F.F. and Huang, Y.W. (2010), “Determinants of users' intention to adopt wireless technology: an empirical study by integrating TTF with TAM", Computers in Human Behavior, Vol. 26 No. 5, pp. 906-915.

Zailani, S., Fernando, Y. and Zakaria, H. (2010), "Determinants of RFID adoption among logistics service providers in Malaysia: a discriminant analysis", International Journal of Logistics Systems and Management, Vol. 7 No. 3, pp. 345-367.

Zailani, S., Iranmanesh, M., Nikbin, D. and Beng, J.K.C. (2015), "Determinants of RFID adoption in Malaysia's healthcare industry: occupational level as a moderator", Journal of Medical Systems, Vol. 39 No. 1, pp. 1-1.

\section{Further reading}

Cao, Q., Baker, J., Wetherbe, J.C. and Gu, V.C. (2012), Organizational Adoption of Innovation: Identifying Factors that Influence RFID Adoption in the Healthcare Industry, ECIS, p. 94.

Chong, A.Y.L., Liu, M.J., Luo, J. and Keng-Boon, O. (2015), "Predicting RFID adoption in healthcare supply chain from the perspectives of users", International Journal of Production Economics, Vol. 159, pp. 66-75.

Hawkes, C.V. and Sullivan, J.J. (2001), "The impact of herbivory on plants in different resource conditions: a meta-analysis”, Ecology, Vol. 82 No. 7, pp. 2045-2058.

Hossain, A.M. (2014), "Development of an integrated model for RFID extension”, Business Process Management Journal, Vol. 20 No. 5, pp. 752-772. 
APJIE

10,1

86

Kamoun, F. and Miniaoui, S. (2015), "Towards a better understanding of organizational adoption and diffusion of RFID technology: a case study approach", International Journal of Technology Diffusion, Vol. 6 No. 3, pp. 1-20.

Lee, D. and Jeong, S. (2010), "The effects of trust and perceived risk for the RFID acceptance intention in the companies", Entrue Journal of Information Technology, Vol. 9 No. 1, pp. $61-76$.

Lim., S.H. (2009), A Study on the Relationship Between Technology Appropriateness and RFID Adoption Intention, Inha University Press, Incheon.

Lim., S.H. (2011), "Roles of trust, fits, and risk on the intention towards RFID acceptance: focused on logistics and retail sectors", Korea Logistics Review, Vol. 21 No. 3, pp. 5-40.

Mayeres, I. and Proost, S. (2001), "Marginal tax reform, externalities and income distribution", Journal of Public Economics, Vol. 79 No. 2, pp. 343-363.

Poston, R. and Grabski, S. (2000), "The impact of enterprise resource planning systems on firm performance", Proceedings of the Twenty First International Conference on Information Systems, December, Association for Information Systems, pp. 479-493.

Reyes, P.M., Li, S. and Visich, J.K. (2016), "Determinants of RFID adoption stage and perceived benefits", European Journal of Operational Research, Vol. 254 No. 3, pp. 801-812.

Tsai, M.C., Lai, K.H. and Hsu, W.C. (2013), “A study of the institutional forces influencing the adoption intention of RFID by suppliers", Information \& Management, Vol. 50 No. 1, pp. 59-65.

Unnithan, C. and Tatnall, A. (2014), "Actor-Network Theory (ANT) based visualisation of socio-technical facets of RFID technology translation: an Australian hospital scenario", International Journal of Actor-Network Theory and Technological Innovation (IJANTTI), Vol. 6 No. 1, pp. 31-53.

Wamba, S.F., Lefebvre, L.A. and Lefebvre, E. (2006), "Enabling intelligent B-to-B eCommerce supply chain management using RFID and the EPC network: a case study in the retail industry", Proceedings of the 8th International Conference on Electronic Commerce: The New E-Commerce: Innovations for Conquering Current Barriers, Obstacles and Limitations to Conducting Successful Business on the Internet, August, ACM, pp. 281-288.

Wyld, D.C. (2005), RFID: The Right Frequency for Government, IBM Center for the Business of Government, Washington, DC.

\section{Corresponding author}

Kwangho Jung can be contacted at: kwjung@snu.ac.kr 


\begin{tabular}{|c|c|c|c|c|c|c|c|}
\hline Variables & Elements of variable & $N$ & Mean effect size & $\mathrm{SD}$ & Minimum & Maximum & \multirow{4}{*}{87} \\
\hline \multirow[t]{3}{*}{ Organizational factor } & \multirow{3}{*}{$\begin{array}{l}\text { Firm size } \\
\text { Financial readiness } \\
\text { Technology } \\
\text { readiness }\end{array}$} & 10 & 0.304 & 0.298 & 0.007 & 0.847 & \\
\hline & & 5 & 0.326 & 0.219 & 0.010 & 0.627 & \\
\hline & & 29 & 0.429 & 0.314 & 0.012 & 1.090 & \\
\hline \multirow[t]{3}{*}{ Technological factor } & Appropriateness & 13 & 0.420 & 0.252 & 0.011 & 1.003 & \\
\hline & Benefit & 19 & 0.479 & 0.312 & 0.182 & 0.845 & \\
\hline & Usefulness & 10 & 0.544 & 0.243 & 0.200 & 1.058 & \\
\hline \multirow[t]{2}{*}{ Environmental factor } & External pressure & 25 & 0.390 & 0.246 & 0.019 & 0.826 & Table AI. \\
\hline & State intervention & 10 & 0.400 & 0.306 & 0.038 & 0.901 & Descriptive statistics \\
\hline
\end{tabular}

\begin{tabular}{|c|c|c|c|c|c|c|}
\hline Variables & $N$ & Mean & $\mathrm{SD}$ & Minimum & Maximum & \\
\hline \multicolumn{7}{|l|}{ Dependent Variables } \\
\hline O-factor & 44 & 0.389 & 0.301 & 0.007 & 1.09 & \\
\hline T-factor & 42 & 0.476 & 0.276 & 0.011 & 1.293 & \\
\hline E-factor & 35 & 0.393 & 0.260 & 0.019 & 0.901 & \\
\hline \multicolumn{7}{|l|}{ Independent variables } \\
\hline \multicolumn{7}{|l|}{ Paper characteristics } \\
\hline Year (publication year) & 121 & 2009.901 & 2.115 & 2006 & 2015 & \\
\hline L_SN (log of sample size) & 121 & 5.051 & 0.474 & 3.912 & 6.353 & \\
\hline \multicolumn{7}{|l|}{ Industry } \\
\hline Manufacture & 79 & 17.853 & 17.376 & 0 & 63.190 & \\
\hline Retail & 82 & 23.067 & 25.263 & 0 & 100.000 & \\
\hline IT & 67 & 20.217 & 16.419 & 0 & 62.900 & \\
\hline \multicolumn{7}{|l|}{ Company type } \\
\hline CM (chief manager) & 68 & 23.676 & 15.289 & 3.400 & 74.00 & \\
\hline LC (large company) & 82 & 30.665 & 21.085 & 0 & 1 & \\
\hline \multicolumn{7}{|l|}{ Region (Dummy variable) } \\
\hline North America & 121 & 0.091 & 0.289 & 0 & 1 & Table AII. \\
\hline Southeast Asia & 121 & 0.231 & 0.423 & 0 & 1 & Descriptive statistics \\
\hline
\end{tabular}




\begin{tabular}{|c|c|c|c|c|c|}
\hline \multirow{5}{*}{$\begin{array}{l}\text { APJIE } \\
10,1\end{array}$} & Study ID & $N$ of O-factor & $N$ of T-factor & $N$ of E-factor & Total \\
\hline & 1 & 1 & 2 & 0 & 3 \\
\hline & 2 & 3 & 0 & 0 & 3 \\
\hline & 3 & 2 & 1 & 0 & 3 \\
\hline & 4 & 1 & 0 & 1 & 2 \\
\hline \multirow{34}{*}{88} & 5 & 1 & 2 & 1 & 4 \\
\hline & 6 & 0 & 1 & 1 & 2 \\
\hline & 7 & 1 & 1 & 2 & 4 \\
\hline & 8 & 1 & 0 & 1 & 2 \\
\hline & 9 & 2 & 0 & 0 & 2 \\
\hline & 10 & 1 & 1 & 1 & 3 \\
\hline & 11 & 0 & 1 & 1 & 2 \\
\hline & 12 & 1 & 2 & 2 & 5 \\
\hline & 13 & 2 & 1 & 2 & 5 \\
\hline & 14 & 2 & 1 & 0 & 3 \\
\hline & 15 & 0 & 1 & 0 & 1 \\
\hline & 16 & 1 & 1 & 1 & 3 \\
\hline & 17 & 0 & 1 & 2 & 3 \\
\hline & 18 & 0 & 1 & 0 & 1 \\
\hline & 19 & 1 & 0 & 0 & 1 \\
\hline & 20 & 2 & 2 & 1 & 5 \\
\hline & 21 & 2 & 0 & 2 & 4 \\
\hline & 22 & 0 & 2 & 1 & 3 \\
\hline & 23 & 2 & 1 & 1 & 4 \\
\hline & 24 & 1 & 1 & 1 & 3 \\
\hline & 25 & 3 & 2 & 3 & 8 \\
\hline & 26 & 1 & 1 & 1 & 3 \\
\hline & 27 & 0 & 0 & 1 & 1 \\
\hline & 28 & 1 & 1 & 0 & 2 \\
\hline & 29 & 0 & 2 & 1 & 3 \\
\hline & 30 & 1 & 0 & 0 & 1 \\
\hline & 31 & 1 & 1 & 2 & 4 \\
\hline & 32 & 1 & 1 & 0 & 2 \\
\hline & 33 & 0 & 1 & 1 & 2 \\
\hline & 34 & 1 & 1 & 0 & 2 \\
\hline & 35 & 1 & 2 & 1 & 4 \\
\hline & 36 & 0 & 1 & 0 & 1 \\
\hline & 37 & 0 & 1 & 1 & 2 \\
\hline & 38 & 1 & 2 & 0 & 3 \\
\hline Table AIII. & 39 & 2 & 0 & 1 & 3 \\
\hline Number of & 40 & 4 & 3 & 2 & 9 \\
\hline observations & Total & 44 & 42 & 35 & 121 \\
\hline
\end{tabular}




\section{Appendix 2}

Determinants

of RFID

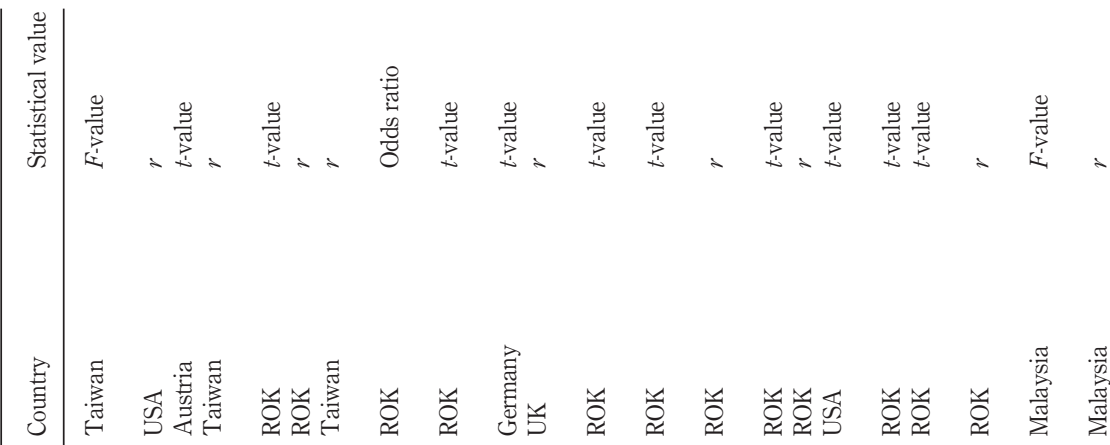

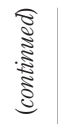

adoption

89

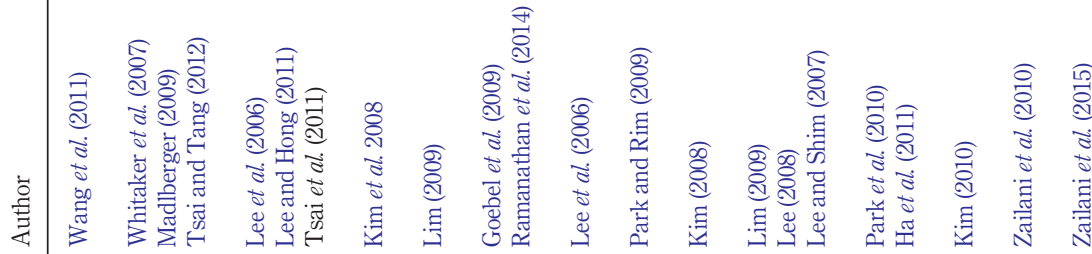

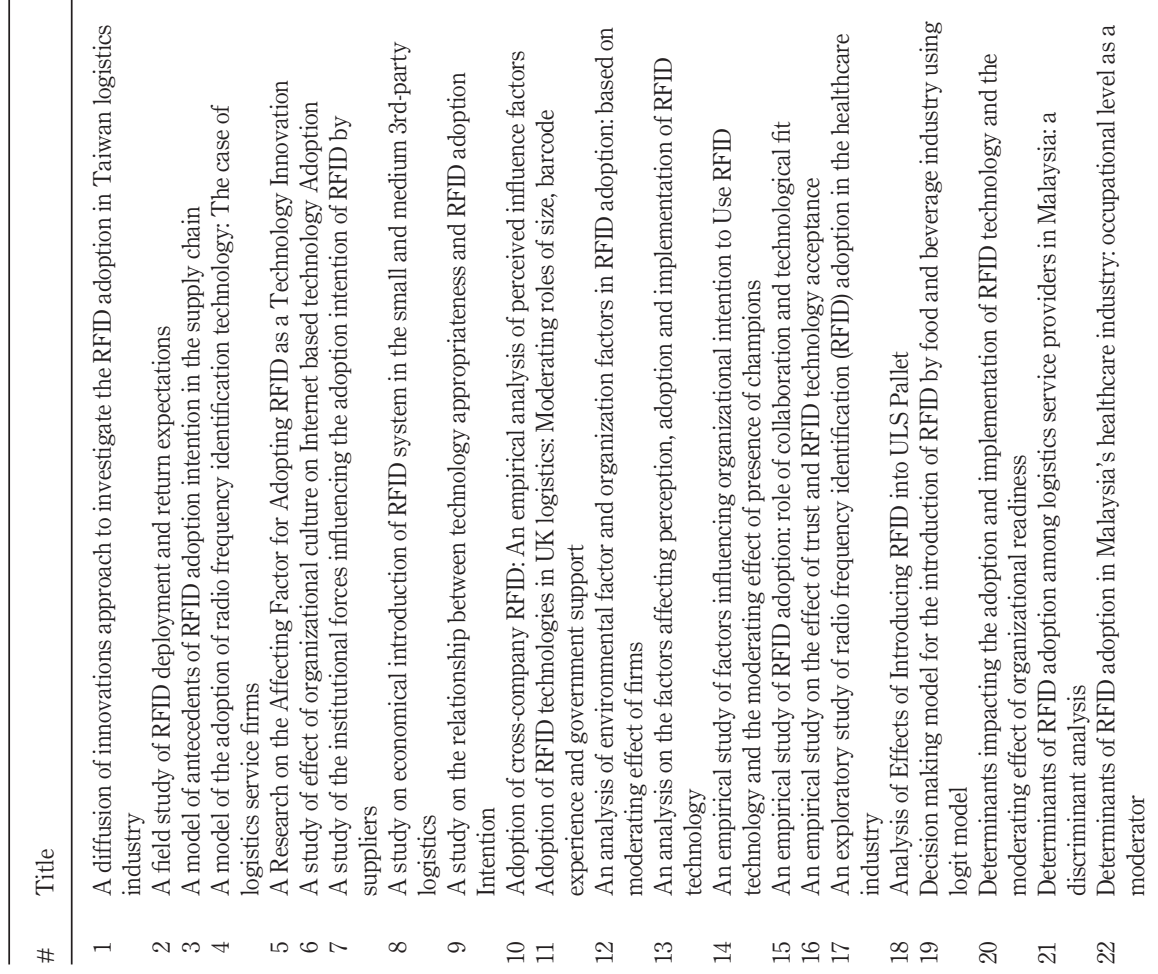

Table AIV.

List of literature for meta-analysis 
APJIE

10,1

90

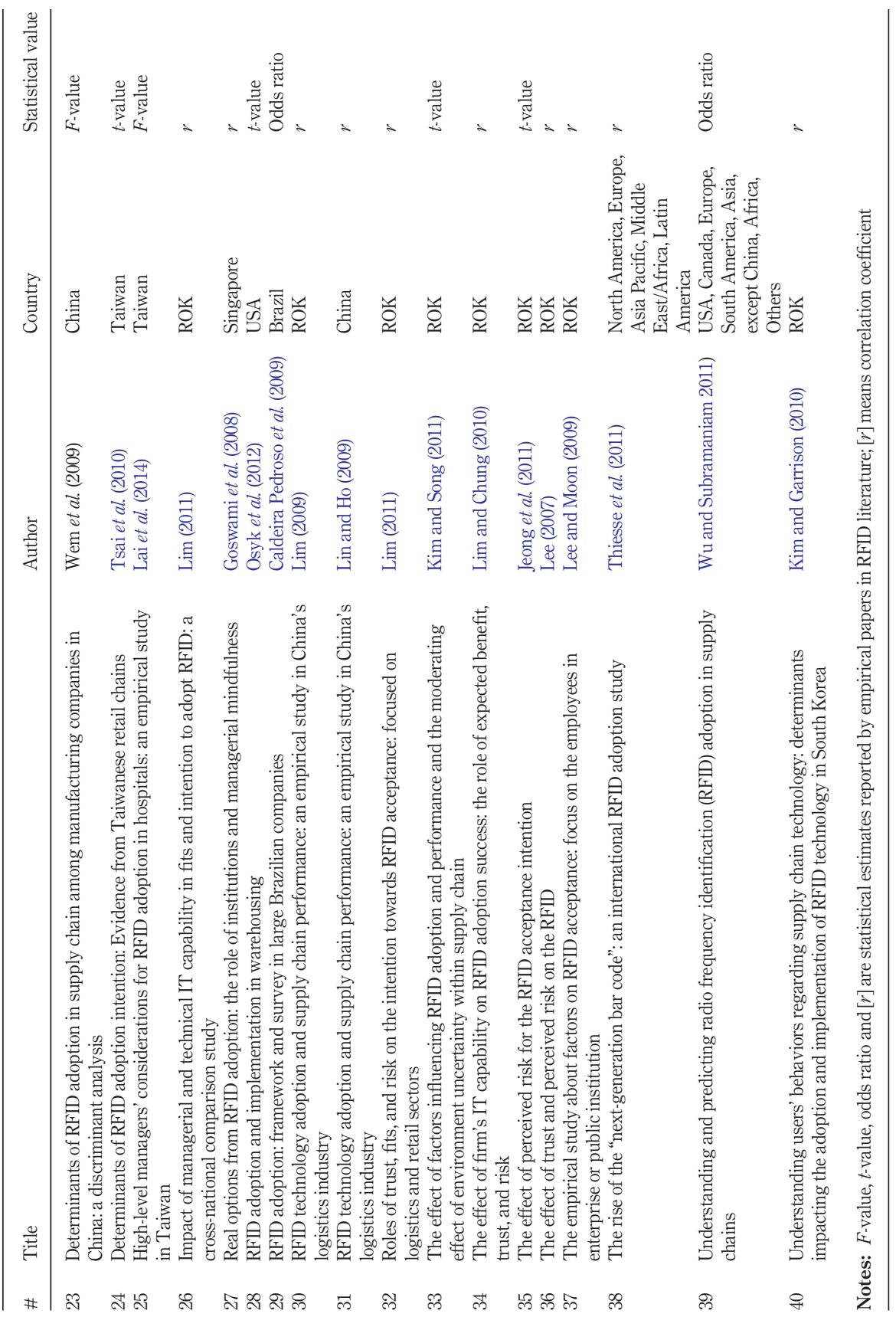

Table AIV. 